\title{
Notes
}

MARINE MAMMAL SCIENCE, 18(3):779-786 (July 2002)

(C) 2002 by the Society for Marine Mammalogy

\section{KILLER WHALE (ORCINUS ORCA) DISTRIBUTION AND ABUNDANCE IN THE CENTRAL AND SOUTHEASTERN BERING SEA, JULY 1999 AND JUNE 2000}

Predation by killer whales (Orcinus orca) has been advanced as a factor in the decline of two marine mammals in Alaskan waters: the sea otter (Enhydra lutris) and the Steller sea lion (Eumetopias jubatus). Estes et al. (1998) implicated killer whale predation as the likely cause for the recent decline of the sea otter population in the Aleutian Islands, due, in part, to the lack of observations of killer whale predation on sea otters in the 1980 s contrasted with recent observations. An investigation of the possibility that killer whales were responsible for the decline in Steller sea lions in Alaska concluded that killer whale predation probably did not cause the decline, but now that the sea lion population is relatively small, killer whale predation may be a contributing factor to further decline. ${ }^{1}$ Our objective was to estimate the abundance of killer whales in the Bering Sea as a first step in evaluating these predation hypotheses.

The presence of killer whales in the Bering Sea has been documented since 1958, from sightings contributed to the Platform of Opportunities Program (POP) at the National Marine Mammal Laboratory (NMML) (Braham and Dahlheim 1982, Dahlheim 1997). Killer whales were observed throughout the Bering Sea, with concentrations north of Unimak Pass and along the Bering Sea shelf. These sightings cannot be used for abundance estimation because there are no estimates of survey effort. POP data also provide a skewed picture of the distribution of killer whales since activity is concentrated in fishing or shipping areas. Few dedicated surveys have been conducted in the Bering Sea for determining killer whale abundance. Leatherwood et al. (1983) conducted aerial surveys in the Bering Sea in the early 1980s, but did not estimate abundance. Aerial surveys conducted in 1985 in the southeastern

\footnotetext{
${ }^{1}$ Barrett-Lennard, L. G., K. Heise, E. Saulitis, G. Ellis and C. Matkin. 1995. The impact of killer whale predation on Steller sea lion populations in British Columbia and Alaska. Report for the North Pacific Universities Marine Mammal Consortium. University of British Columbia, Fisheries Centre, 2204 Main Mall, Vancouver, BC V6T 1Z4, 71 pP. http:/www.marinemammal.org/ pdfs/Barrett_etal1995-killer.pdf
} 
Bering Sea ${ }^{2}$ were separated into roughly two areas along the $165^{\circ}$ longitude line, the North Aleutian Basin to the east and the St. George Basin to the west. An abundance estimate of $639 \pm 476$ killer whales was calculated for the St. George Basin (uncorrected for submerged or missed animals) but abundance was not estimated for the North Aleutian Basin (which includes Bristol Bay) due to the low number of sightings. In 1992 and 1993 a total of 170 individual killer whales were photo-identified primarily along the eastern Aleutian Islands and the Bering Sea shelf from Unalaska Island to the Pribilof Islands, representing a small portion of the Bering Sea (Dahlheim 1997). 3.4

We conducted line-transect surveys for cetaceans aboard an acoustic-trawl survey for walleye pollock (Theragra chalcogramma) on the Bering Sea shelf in July 1999 and June 2000. The trawl survey consisted of 29 north-south transect lines spaced $37 \mathrm{~km}(20 \mathrm{nmi})$ apart and proceeded from east to west scheduled in two legs: leg 1 consisted of lines 1-18 (Fig. 1) and leg 2 of lines 19-29 (Fig. 2). We participated in leg 2 in 1999 and leg 1 in 2000. Together, the two legs provided an opportunity to survey the central and southeastern Bering Sea shelf. Visual surveys were conducted from the flying bridge of the NOAA ship Miller Freeman (66 m in length) along predetermined tracklines of the acoustic pollock survey. The height of the platform was $12 \mathrm{~m}$ and the ship traveled at $19-22 \mathrm{~km} / \mathrm{h}$. In both years additional surveys were conducted for cetaceans apart from the 29 trawl survey lines. In 1999, surveys were conducted during transit to and from Dutch Harbor, in Bristol Bay, and on transect lines in waters termed the "Horseshoe Area" north of Unimak Pass (Fig. 2). The 2000 cetacean survey included part of the transit from Kodiak Island to Unimak Pass in the Gulf of Alaska (Fig. 1). Sightings from these additional surveys are referred to as "extra-effort" sightings.

Line-transect survey protocols were used, with two observers using $25 \times$ 150 power binoculars at port and starboard stations, and a centered data recorder. The port observer surveyed from $10^{\circ}$ right to $90^{\circ}$ left of the trackline and the starboard observer surveyed $10^{\circ}$ left to $90^{\circ}$ right of the trackline. The recorder scanned the entire $180^{\circ}$ area forward of the ship, using Fujinon 7 $\times 50$ reticled binoculars to confirm sightings. The ship's global positioning system (GPS) unit interfaced with a portable computer at the recorder's station. The date, time, and position of the vessel were automatically entered into the

\footnotetext{
${ }^{2}$ Brueggeman, J. J., G. A. Green, R. A. Grotefendt and D. G. Chapman. 1987. Aerial surveys of endangered cetaceans and other marine mammals in the northwestern Gulf of Alaska and southeastern Bering Sea. Report on Contract No. 85-ABC-00093. Minerals Management Service and NOAA Office of Oceanography and Marine Assessment, Alaska Office (OCSEAP Research Unit 673), 949 East 36th Ave, Anchorage, AK 99508, 129 pp.

'Dahlheim, M. E., and J. M. Waite. 1993. Abundance and distribution of killer whales (Orinus orca) in Alaska in 1992. Annual Report for 1992 to the Office of Protected Resources, NMFS, NOAA, 1335 East-West Highway, Silver Spring, MD 20910, 29 pp.

"Dahlheim, M. E. 1994. Abundance and distribution of killer whales, Orcinus orca, in Alaska, 1993. Annual Report for 1993 to the Office of Protected Resources, NMFS, NOAA, 1335 EastWest Highway, Silver Spring, MD 20910, 18 pp.

'Reference to trade names does not constitute endorsement by the National Matine Fisheries Service.
} 


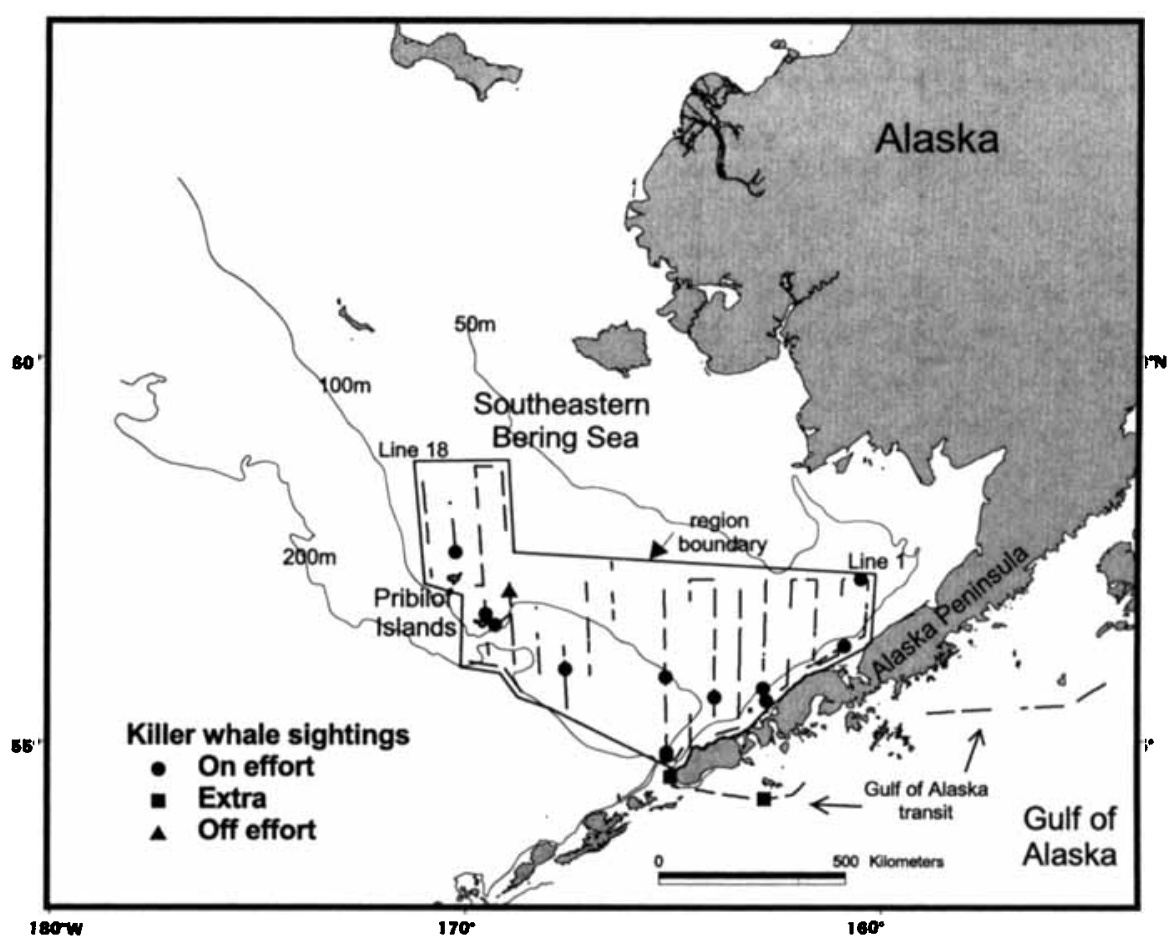

Figure 1. Completed trackline and killer whale sightings for the 2000 cetacean survey during walleye pollock trawl survey.

survey program every $10 \mathrm{~min}$ and whenever data were entered by the recorder. At the start of each trackline, waypoints, observer positions, and environmental conditions were entered. Environmental conditions included sea state (Beaufort scale), weather (rain, fog, no rain or fog, both rain and fog), and, for each observer, visibility (an overall determination from excellent to unacceptable of how each observer judged sighting conditions; in 2000 only), and glare (no glare, minor glare, extreme glare, or reflective glare where there is no direct glare but the surface of the water has a foil-like reflection). Species, vertical distance (taken from reticles in the binoculars), angle relative to the ship's heading (from an angle ring on the binocular mount), and group size were recorded for each sighting. In 1999 the observers did not rotate. In 2000 the observers rotated positions every 30 min during a 2 -h shift, followed by a 30 min break. In both years, the survey was suspended when the ship stopped for fishing operations, during inclement weather (fog or Beaufort $>5$ ), and when light levels were too low for efficient observations.

Data were divided into three strata: the 1999 central Bering Sea shelf, the 2000 southeastern Bering Sea shelf, and the additional surveys from both years (transits and the "Horseshoe Area"). Sightings were then grouped into three types: on-effort sightings made under survey protocol along the trawl survey lines on the central and southeastern Bering Sea shelf, extra-effort sightings 


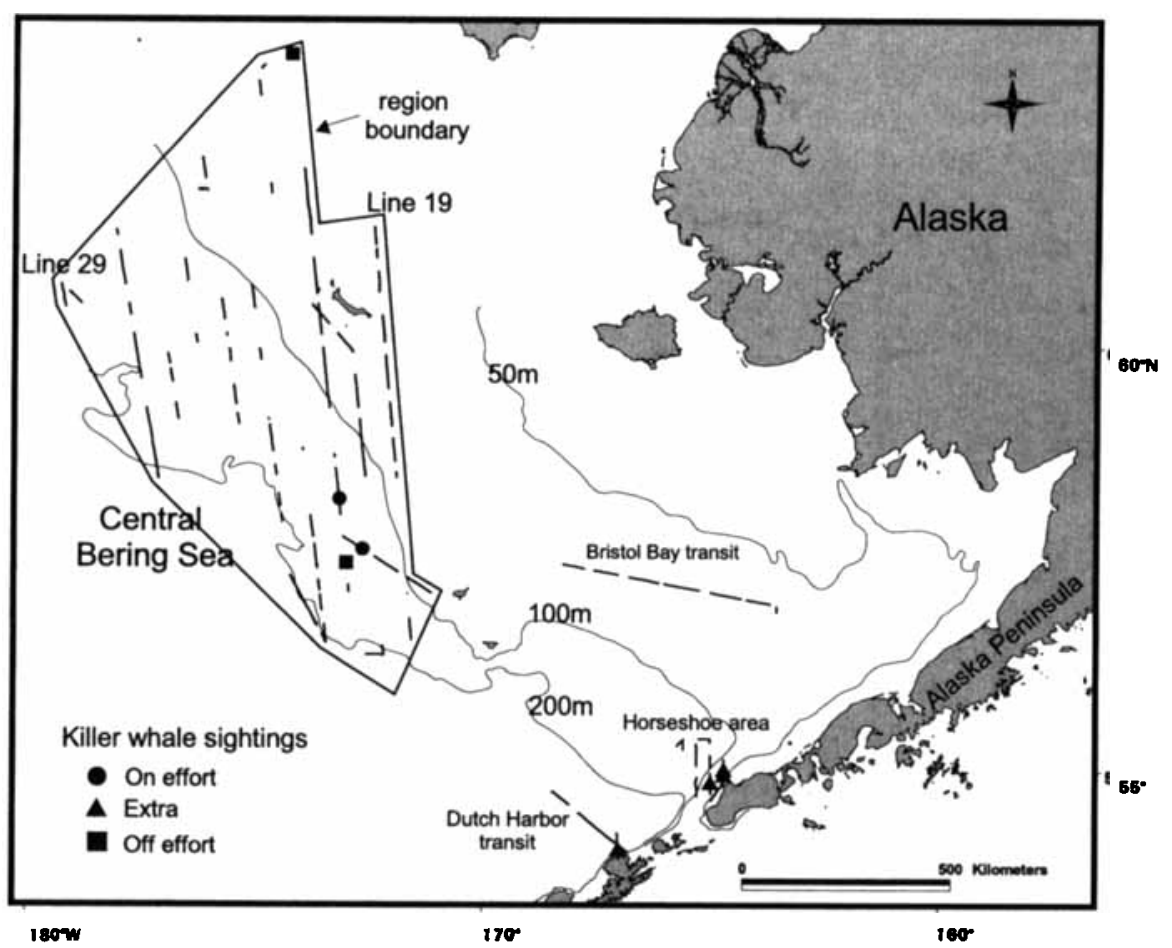

Figure 2. Completed trackline and killer whale sightings for the 1999 cetacean survey during walleye pollock trawl survey.

made under survey protocol during the additional surveys, and off-effort sightings that did not occur under survey protocol. The additional surveys were not included as effort in the abundance estimates, but perpendicular distances from extra-effort sightings were included for determination of the detection function. Off-effort sightings were only used to depict distribution.

The kilometers of trackline covered in each Beaufort sea state and average killer whale perpendicular distance were examined for each strata. Since the average survey conditions in each strata were similar, a pooled detection curve and effective strip width were estimated using sightings from all strata. Killer whale group size, density, and abundance were estimated for 1999 and 2000 separately. The abundance for strata $i, \mathrm{~N}_{i}$, was calculated as:

$$
N_{i}=\frac{n_{i} f(0) \bar{s}_{i} A_{i}}{2 L_{i}}
$$

where $A_{i}$ is the size of the study area $i, \bar{s}_{i}$ is the average number of whales per useable on-effort sighting in strata $i, n_{i}$ is the number of useable on-effort sightings in strata $i, f(0)$ is the probability density function of sighting distances from the trackline evaluated at zero distance, and $L_{i}$ is the total length of the useable effort segments in strata $i$. Analyses were conducted using the program DISTANCE (Thomas et al. 1998). The study area was defined as the 
area enclosed by a boundary $10 \mathrm{~km}$ beyond the limits of the survey tracklines (the approximate viewing extent of the observers), calculated as $196,885 \mathrm{~km}^{2}$ in 1999 and $158,561 \mathrm{~km}^{2}$ in 2000 using ArcView ${ }^{\text {TM }}$ (3.1).

A radial sighting distance for each sighting was calculated using the reticle reading and the height of the platform as in Lerczak and Hobbs (1998). The perpendicular distance between a sighting and the trackline was estimated as the product of the radial distance to sightings and the sine of the radial angle of the sighting. For estimating abundance, perpendicular distances were truncated at $7 \mathrm{~km}$ from the trackline as 19 of the 20 useable sightings were within this range and the 20th was at $11.24 \mathrm{~km}$. Perpendicular sighring distances were grouped into five bins such that the first three bins were $1.0 \mathrm{~km}$ wide and the remaining bins were $1.5 \mathrm{~km}$ wide. Wider bin widths were chosen farther from the trackline because measurement error increases with distance from the trackline. However, four bins $1.75 \mathrm{~km}$ wide, as well as a variety of other binning structures, produced comparable results. The probability of sighting with respect to perpendicular distance from the trackline was modeled using the uniform and half-normal key functions, with either the cosine or simple polynomial series expansion, and the hazard rate key function, with either the cosine or Hermite polynomial series expansion. Akaiki's Information Criteria (AIC) were used to determine both the number of expansion terms and the best-fit of the six models. The strip width was estimated as twice the integral of the detection function $(g(x))$ evaluated from the trackline to the truncation point.

Tracklines began and ended whenever there was a significant shift in survey effort as indicated by changes in sighting conditions (visibility, Beaufort sea state), personnel, or vessel speed and direction. Because of the limitations of the survey, data were not collected and estimates were not corrected for animals missed on the trackline (perception bias) or animals submerged when the ship passed (availability bias), and thus $g(0)$ is assumed to be 1 . Estimates were also not corrected for responsive movement (avoidance of or attraction to the survey vessel). The potential magnitude of these biases are unknown but are not expected to be large since killer whales surface frequently and are relatively conspicuous cetaceans.

Because smaller groups are less likely to be seen farther from the trackline than larger groups, mean group size can be positively biased. To avoid this potential positive bias, expected group size was computed as the regression of the $\log$ of the observed group sizes on the detection probability, unless the regression was not significant. Because this bias has been shown to occur in other data sets, a significance level of 0.15 , rather than 0.05 , was used to increase the probability of capturing any signal of smaller groups not seen farther from the trackline.

In 1999 the cruise began and ended in Dutch Harbor, Alaska, and extended from 5 July through 5 August 1999. A total of $1,761 \mathrm{~km}$ of trackline were surveyed in the central Bering Sea, and $609 \mathrm{~km}$ were surveyed during transit and in the Horseshoe area. In 2000 the survey began in the Gulf of Alaska, west of Kodiak Island and ended at Dutch Harbor, Alaska, extending from 


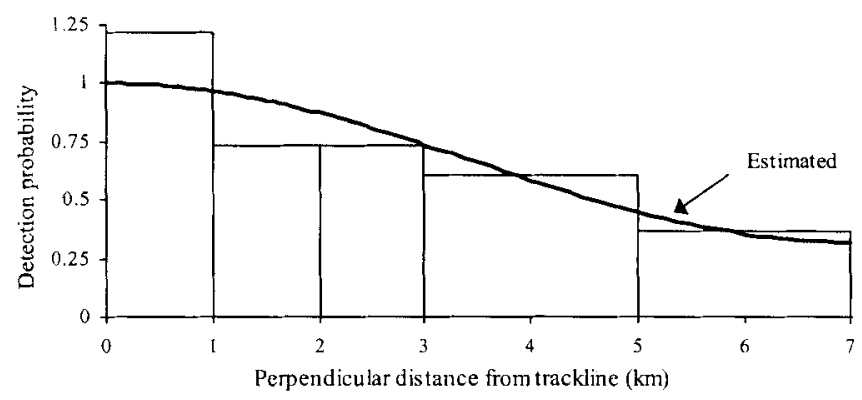

Figure 3. Distribution of perpendicular distances for killer whales sighted under survey protocols in 1999 and 2000 with the detection function $[G(x)]$ fit as a uniform key function with one cosine series expansion term.

10 June to 3 July 2000 . A total of $2,194 \mathrm{~km}$ of trackline was surveyed in the southeastern Bering Sea and $401 \mathrm{~km}$ surveyed during transit. In 1999 there were only two on-effort killer whales sightings in the survey region, four extraeffort sightings in the Horseshoe and Dutch Harbor transit area, and two offeffort sightings (Fig. 2). In 2000 there were 11 on-effort sightings in the survey region, two extra-effort sightings in the Gulf of Alaska transit, and one off-effort sighting (Fig. 1).

With a truncation distance of $7.0 \mathrm{~km}$ (Fig. 3), the best-fit model for the detection curve was the uniform key function with one cosine series expansion term $($ AIC $=64.32$, goodness-of-fit chi-square test probability $=0.94)$. In 1999 and 2000 the expected group size was computed as the average of the observed group sizes because there were only two sightings in 1999 and the regression of the $\log$ of the group size on the detection probability was not significant in 2000 .

The estimated abundance of killer whales on the southeastern Bering Sea shelf in 2000 was 391 (95\% CI $=171-894$ ) (Table 1). It is difficult to compare this estimate to the 1985 aerial survey estimate of $639(95 \% \mathrm{CI}=$ $163-1,115)$ killer whales in the St. George Basin ${ }^{2}$ since the 1985 area is only a portion of our southeastern Bering Sea shelf area. In addition, neither estimate has been corrected for missed or submerged animals, and the correction factors are likely to be different for aerial and shipboard surveys. Although the 1985 point estimate is greater than our 2000 estimate, the confidence intervals for the 1985 estimate encompasses the confidence interval for our 2000 estimate. Because there were only two on-effort sightings on the central Bering Sea shelf in 1999, abundance was not estimated for this strata.

Most killer whales were seen near the Alaska Peninsula and the Pribilof Islands, with scattered sightings along the 100-m depth contour (Fig. 1, 2). Sightings were scattered throughout the longitudinal range of $174^{\circ} \mathrm{W}$ to $160^{\circ} \mathrm{W}$ and there were no sightings west of longitude $174^{\circ} \mathrm{W}$, suggesting that killer whales may be more numerous in the waters of the southeastern Bering Sea shelf than the central Bering Sea shelf. This distribution pattern is contrary to that found on aerial surveys of the southeastern Bering Sea in 1985 where 
Table 1. Killer whale abundance estimate and related parameters.

\begin{tabular}{|c|c|c|c|c|c|}
\hline & \multirow{2}{*}{$\begin{array}{l}\text { Point } \\
\text { estimate }\end{array}$} & \multirow{2}{*}{$\begin{array}{l}\text { Standard } \\
\text { error }\end{array}$} & \multirow{2}{*}{$\%$} & \multicolumn{2}{|c|}{$\begin{array}{l}95 \% \text { Confidence } \\
\text { interval }\end{array}$} \\
\hline & & & & (Lower) & (Upper) \\
\hline \multicolumn{6}{|c|}{ Combined data for detection function } \\
\hline Number of sightings & 19 & & & & \\
\hline Truncation distance $(\mathrm{km})$ & 7 & & & & \\
\hline Effective strip width $(\mathrm{km})$ & 4.6 & 0.9 & 20 & 3.1 & 7.0 \\
\hline \multicolumn{6}{|l|}{1999 central Bering Sea shelf ${ }^{a}$} \\
\hline Number of sightings & 2 & & & & \\
\hline Length of trackline $(\mathrm{km})$ & 1,761 & & & & \\
\hline Area $\left(\mathrm{km}^{2}\right)$ & 196,885 & & & & \\
\hline Sighting rate & 0.0011 & 0.0008 & 67 & 0.0003 & 0.038 \\
\hline Average group size & 5.0 & 4.0 & 80 & 1 & 38,037 \\
\hline \multicolumn{6}{|c|}{2000 southeastern Bering Sea shelf } \\
\hline Number of sightings & 11 & & & & \\
\hline Length of trackline $(\mathrm{km})$ & 2,194 & & & & \\
\hline Area $\left(\mathrm{km}^{2}\right)$ & 158,561 & & & & \\
\hline Sighting rate & 0.0050 & 0.0013 & 25 & 0.0031 & 0.0082 \\
\hline Average group size & 4.5 & 1.3 & 28 & 2.4 & 8.4 \\
\hline Estimated density & 0.0025 & 0.0011 & 43 & 0.0011 & 0.0056 \\
\hline Estimated abundance & 391 & 168 & 43 & 171 & 894 \\
\hline
\end{tabular}

${ }^{a}$ Due to low number of sightings, abundance and density were not calculated for 1999 on the central Bering Sea shelf.

sightings occurred only between $167^{\circ} \mathrm{W}$ and $163^{\circ} \mathrm{W} \cdot{ }^{2}$ However, because killer whales are highly mobile one would not expect the distribution to be entirely consistent among years.

Two types of killer whales have been distinguished in the Pacific Northwest, including coastal waters of Washington, British Columbia, and southern Alaska (Bigg et al. 1990, Morton 1990, Barrett-Lennard et al. 1996, Ford et al. 1998): resident-type whales, which primarily eat fish, and transient-type whales, which primarily eat mammals. The abundance estimate and distribution patterns presented here likely include both types. Long-term photoidentification studies coupled with genetic analyses will be necessary to distinguish killer whale types for determining what fraction of the killer whale population might contribute to the decline of sea otters and Steller sea lions.

\section{ACKNOWLEDGMENTS}

We thank Mike Newcomer, Todd Pusser, and Lori Mazzuca for their expertise and dedication during long hours of visual survey. Todd Pusser also acted as Lead Scientist during the 1999 survey. We thank Gary Stauffer (NMFS/RACE) who supported our efforts by providing ship access. The flexibility and assistance of the captain and crew of the NOAA ship Miller Freeman contributed to the success of the research. Neal Williamson and Bill Karp, Chief Party Scientists, allowed diversions from the pollock survey for data confirmation. Thanks are extended to all of the RACE/MACE scientists 
for their flexibility and support. Paul Wade provided valuable assistance in data analysis. Valuable reviews were provided by Douglas DeMaster, James Lee, Gary Duker, and two anonymous reviewers which greatly improved this manuscript. Grant support for this research was provided by the National Marine Fisheries Service, National Oceanic and Atmospheric Administration, U.S.A. This research was conducted under Permit No. 782-1438 issued by the National Marine Fisheries Service.

\section{Literature Cited}

Barrettr-Lennard, L. G. B, J. K. B. Ford anid K. A. Heise. 1996. The mixed blessing of echolocation: Differences in sonar use by fish-eating and mammal-eating killer whales. Animal Behaviour 51:553-565.

Bigi, M. A., P. F. OifesitK, G. M. Ellis, J. K. B. Ford and K. C. Balcomb III. 1990. Social organization and genealogy of resident killer whales (Orinus orca) in the coastal waters of British Columbia and Washington State. Reports of the International Whaling Commission (Special Issue 12):386-405.

Braham, H. W., And M. E. Dahluheim. 1982. Killer whales in Alaska documented in the Platforms of Opportunity Program. Report of the International Whaling Commission 32:643-646.

Dahlheim, M. E. 1997. A photographic catalog of killer whales, Orcinus oria, from the central Gulf of Alaska to the southeastern Bering Sea. U.S. Department of Commerce, NOAA Technical Report NMFS-130. $58 \mathrm{pp}$.

Estes, J. A., M. T. Tinker, T. M. Williams and D. F. Doa. 1998. Killer whale predation on sea otters linking oceanic and nearshore ecosystems. Science 282: $473-475$.

Ford, J. K. B., G. M. Ellis, L. G. Barrett-Lennard, A. B. Morton, R. S. Palmand K. C. Balcomb. 1998. Dietary specialization in two sympatric populations of killer whales (Orcinus orca) in coastal British Columbia and adjacent waters. Canadian Journal of Zoology 76:1456-1471.

Leather wood, S., A. Bowles and R. Reeves. 1983. Endangered whales of the eastern Bering Sea and Shelikof Strait, Alaska: Results of aerial surveys, April 1982 through April 1983 with notes on other marine mammal behavior. Hubbs/Sea World Research Institute Technical Report 83-159:173-182.

Lerczak, J. A., and R. C. Hobbs. 1998. Calculating sighting distances from angular readings during shipboard, aerial, and shore-based marine mammal surveys. Marine Mammal Science 14:590-599 and Errata 14:903.

Morton, A. B. 1990. A quantitative comparison of the behavior of resident and transient forms of the killer whale off the central British Columbia coast. Reports of the International Whaling Commission (Special Issue 12):245-248.

Thomas, L., J. L. Laake, J. F. Derry, S. T. Buckland, D. L. Borchers, D. R. Anderson, K. P. Burnham, S. Strindberg, S. L. Heidley, M. L. Burt, F. Marques, J. H. Pollard and R. M. Fewster. 1998. Distance 3.5. Research Unit for Wildlife Population Assessment, University of St. Andrews, UK.

Janice M. Waite, Nancy A. Friday and Sue E. Moore, National Marine Mammal Laboratory, Alaska Fisheries Science Center, NMFS, NOAA, 7600 Sand Point Way NE, Seattle, Washington 98115, U.S.A.; e-mail: Janice.Waite@noaa.gov. Received 8 July 2001. Accepted 13 November 2001. 